\title{
An Experimental Investigation of Vagueness on the Left Side of Balance Sheet
}

\author{
Ricardo Lopes Cardoso ${ }^{\dagger}$ \\ Getulio Vargas Foundation
}

\author{
André Carlos Busanelli de Aquino ${ }^{\Omega}$ \\ University of São Paulo / FEA-RP
}

\begin{abstract}
We investigated through experiments vagueness among property, plant, and equipment (PPE), intangible asset and inventory accounts. To semantic vagueness among items, epistemic vagueness is added in relation to liquidity order classification. Traditional dichotomy current/non-current classification of balance sheet items seems to have been used as a straitjacket, where inventories are current assets, and PPE and intangibles are non-current assets. While gray zone is ignored, items that lay on that are swept under the rug, i.e. arbitrarily classified in one way or another, hence, information asymmetry persists, and is neglected by auditors and standard setters. Literature suggests that the increase of information about underling economic transactions mitigate vagueness. Through the configurational approach, we identified five arrangements according to the intensity of property rights transference. Information about those five arrangements was provided to subjects. Evidences from between-subjects experiments (subjects were 93 MBA students enrolled on Accounting courses) suggest that the argued vagueness is acknowledge by financial statements users.
\end{abstract}

Keywords: classified balance sheet; IFRS; vagueness; experiment.

\footnotetext{
Received in 01/27/2009; revised in 07/21/2009; accept in 08/02/2009.

Corresponding authors*:

$\dagger$

Adjunct Professor, Getulio Vargas Foundation and the University of Rio de Janeiro

Address:Praia de Botafogo, no. 190, sala 501, Rio de Janeiro/RJ - BrazilCEP 22250090

e-mail: ricardo.lopes.cardoso@fgv.br

Telephone: (21) 37995781

$\Omega$ Professor, Faculty of Economics, Management and Accounting of Ribeirão Preto, University of Sao Paulo

Address: Av. Bandeirantes, 3900, Monte Alegre, Ribeirão Preto/SP - Brazil CEP 14040-900

e-mail:aaquino@usp.br

Telephone: (16) 36023899
}

Editor's note: This paper was accepted by Antonio Lopo Martinez 


\section{INTRODUCTION}

A

ccounting standards setters and academics have approached significant efforts on assets valuation, especially on fair value accounting (SUNDER, 2008), and more recently, they have been concern with fair disclosure. Advances in relation to fair value adoption, especially with the increasing use of International FinancialReporting Standards (IFRS) worldwide, bring closely the content of information accounting about assets and liabilities to their economic value. In addition, requirements of regulatory bodies, about fair disclosure, mainly the U.S Securities and Exchange Commission (SEC), has reduced the informational asymmetry among investors and mitigated the power of insiders.

The real ability assets have to provide economic benefits (potential cash inflows) through time are only partially disclosed by these two initiatives (fair value accounting and fair disclosure). Due to the fact that accounting framework and standards are based on principles (or rules) ${ }^{1}$, linguistic imprecision and factual uncertainty may create some gray zones, where logical classification reasoning must be replaced by analogical reasoning (PENNO, 2008). Linguistic imprecision and factual uncertainties are called vagueness and ambiguity $^{2}$. Generally accepted practices are weak correlated to asset's probability to provide cash inflows. This weak sensitivity, especially at the gray zone among inventories, property, plant, and equipment (PPE), and intangible assets, occurs depending on some kind of vagueness present on actual standards concepts. The relevance of vagueness study in accounting is recognized by Zebda (1991), who says that its neglect restricts the applicability and limits usefulness of accounting information.

The ignorance of vagueness on the left side of balance sheet leads to arbitrary classification that may induce potential misleading information by a contractual part seeking to attain an agreed condition, a strategic goal in an executive bonus, a threshold in a public service concession, a covenant in a loan agreement, or a surplus (goodwill) on a business combination transaction. In an agency perspective, the agent (more informed) may mislead the content of accounting information by misclassifying assets and/or liabilities in order to increase the probability to capture a part of principal's residual income. This movement was observed in academic literature on balanced sheet management for debt obligations (CHOUDHRY; FABOZZI, 2003). Since external parties of the company look for information on accounting, the choice of presenting (classifying and disclosing) items among inventory, PPE or intangible assets affects the perception of stakeholders in regards to the entity's value, performance, liquidity and solvency ${ }^{3}$. Those choices also affect the content of managerial performance indicators and consequent decision making in the planning process, for long or short term, and other performance metrics applied in several firms' contracts with suppliers,

\footnotetext{
${ }^{1}$ For the means of this paper, as like as Penno (2008), we do not consider it relevant to distinct rules from principles on accounting regulation.

${ }_{2}^{2}$ Although ambiguity and vagueness are technically different, we use these terms interchangeably. According to Zebda (1991, p.117-8): "Randomness deals with the probabilistic uncertainty concerning the occurrence or nonoccurrence of an event. Ambiguity and vagueness, on the other hand, have to do with imprecision and inexactness of events, stimuli, words, concepts, and judgments [...] Ambiguity exists when a word or concept has multiple meanings and is used to describe distinguishable subconcepts, while vagueness exists when the word or concept lack precise shape and boundaries."

3 According to IASB (2001, paragraph 16), "liquidity refers to the availability of cash in the near future after taking account of financial commitments over this period. Solvency refers to the availability of cash over the longer term to meet financial commitments as they fall due". But we will use the term solvency to refer both to firm's liquidity and firm's solvency.
} 
creditors, shareholders, employees and some governmental offices. Thus financial ratios may be misrepresented in the presence of vagueness, reducing the quality of accounting reports ${ }^{4}$. Balance sheet classification, fair value, and fair disclosure issues help predict discount future cash flows, which are investors' interest in valuing equity and accessing insolvency risk (BARTH, 2008). But vagueness' hazards constraint the disclose effort success of a gray zone assets in accordance to their liquidity ability, decreasing reliability and a faithfully ${ }^{5}$ picture of the real-world economic phenomenon (BARTH, 2008). Vagueness may also reduce the levels of verifiability, relevance and consistency (PENNO, 2008).

Considering some research questions suggested by Barth $(2008,1171)$ about short and long term assets financial reporting, in this article, following the Sōritēs Paradox ${ }^{6}$, is identified a "Liquidity Paradox" and others sources of vagueness, in order to discuss the scale that discriminate items on balanced sheet left side among inventory, PPE, and intangible assets. Through a configurational approach ${ }^{7}$ (DOTY; GLICK, 1994; MEYER ET AL., 1993; MILLER, 1999; MILGROM; ROBERTS, 1995), based on Property Rights Theory (BARZEL, 1989; DEMSETZ, 1988), we can identify five typical arrangements in which goods are traded. Then we show how two traditional dimensions being use by accounting standards and an additional dimension being identify through our configurational approach, are not sufficient to eliminate vagueness on balance sheet taxonomy. Finally, to test the presence of vagueness on IASB's definitions of inventory, PPE and intangible assets, we developed a between-subjects experiment with 93 Brazilian MBA students.

\section{BACKGROUND AND LIQUIDITY PARADOX}

Vagueness (or ambiguity) is a characteristic of an object (words, concepts) related to an insufficient delineation of its meanings' borderlines, created by linguistic imprecision, factual uncertainty, or both. The two potentials causes of indeterminate (gray) zones are: (i) epistemic vagueness, that occurs when a sharp boundary is presumed to exist, but it is unclear where it is, and (ii) semantic vagueness, that occurs when a reliance on language is insufficient to make the classification. Besides epistemic and semantic classifications, vagueness is also classified, based on the number of dimensions on which the concept is

\footnotetext{
${ }^{4}$ Opportunism, as discussed on earnings management literature, is not a condition for misrepresentation on the perspective of vagueness, as discussed in this paper. The presence of vagueness is a sufficient condition, since misrepresentation, here, being not necessarily associated to an intentional action. But, we consider accounting and auditing professionals sufficiently consciousness of their choices and that they consider the costs and benefits of each accounting choice, including the regulator verifiability capacity.

${ }^{5}$ According to FASB (1980, paragraph 63), "Representational faithfulness is correspondence or agreement between a measure or description and the phenomenon it purports to represent. In accounting, the phenomena to be represented are economic resources and obligations and the transactions and events that change those resources and obligations."

${ }^{6}$ According to Hyde (2005), "the following argument form of the Sōritēs was common:

1 grain of wheat does not make a heap.

If 1 grain of wheat does not make a heap then 2 grains of wheat do not.

If 2 grains of wheat do not make a heap then 3 grains do not...

... If 9,999 grains of wheat do not make a heap then 10,000 do not.
}

10,000 grains of wheat do not make a heap.

${ }^{7}$ The configurational approach considers the existence of a "multidimensional constellation of conceptually distinct characteristics that commonly occurs together" (MEYER ET AL., 1993, p.1175), and categorizes potential attributes of a phenomenon in a relative small number of standards, ideal types and internally consistent. Those characteristics set of "ideal types" together describing a large proportion of cases of the phenomenon in question. The most serious criticism of the approach configurationally rejects the theory as real, reducing it to just the simple classification schemes (DOTY; GLICK, 1994; MILLER, 1999). 
analyzed: unidimensional or multi-dimensional. Unidimensional vagueness is concerned to a single attribute, while multi-dimensional is related to $n$ attributes (WILLIAMSON, 1997; 1999a; SCHIFFER, 1999; KEEFE, 1998, 2007; PENNO, 2008).

In order to identify sources of epistemic and semantic vagueness, our analysis considers the liquidity scale, and the categories suggested by accounting standards to classify items on this scale (presented on next section). The first is an epistemic and unidimensional form (or "soretical" form) of vagueness, the second is a multi-dimensional vagueness.

Accounting information seeks to represent faithfully either quantitatively and qualitatively entities' financial position and performance. Quantitative representation is attained by measurement criteria (historical cost, current cost, realizable value, present value). Qualitative representation is made through classifications of accounts or group of accounts on financial reporting (categories: current and noncurrent assets, current and noncurrent liabilities, equity, operating income, extraordinary items, cash flows from operations, investing activities, financing activities, etc.). Anthony and Reece $(1989,32)$ suggest that account categories provides qualitative information, and improves information relevance.

Based on accounting literature, liquidity is the concept (criteria) used to organize items on the left side of balance sheet, and is associated to the promptness, which assets are expected to be converted into cash (ANTHONY; REECE, 1989, p.32). This liquidity concept is ambiguous (it may represent more than one state or object) and semantically vague (there is no clearly meaning borderline for "promptness"). In order to mitigate this problem, we purpose that "promptness" concept would be surrogate by the specificity level of the asset. An asset is specific when it cannot be reallocated, from its original application, to another use without a significant reduction on its value (JOSKOW, 1985). The maximum value of a specific asset occurs when it is applied in the particular purpose for which it was designed. For high levels of specificity, the associated sunk cost reduces the probability of a promptness and costless transference. Joining these two concepts, liquidity is associated to the promptness conversion of an asset (with specificity higher than zero) into another asset (no specific or, at least, less specific), potentially transacted at its face value at any time by any economic agent. At the extreme, promptness is surrogated by the distribution of cash inflows.

In order to accomplish its obligations, the firm is asked about its capacity to convert assets (with high or middle-range specificity) into assets with low specificity, like money. Usually, employees, lenders, and others, and governments seek to receive high liquidity assets, as like cash. Then, through solvency analysis, stakeholders estimate the probability that the entity has to convert its resources (that would not be easily accepted to settle a liability) into items that are easily accepted to settle a liability on normal conditions.

If liquidity level is a continuum scale, and the liquidity of an item is not measurable (quantitatively) ex ante, to ordinate (classify) several items according to their liquiditycut-offs points (limits between potential categories) are necessary. Thus, related to liquidity, there is epistemic vagueness, mitigated in some extend, as well as semantic vagueness and ambiguity. As like as on the Sōritēs paradox, "since we do not know their cut-off points, we cannot calibrate instruments to measure them" (WILLIAMSON, 1997) - what characterizes a borderline case, as presented on figure 1 . Thus, there is a vagueness problem on the left side of balance sheet, which is ignored on accounting standards. An item will be definitely liquid $\left(\mathrm{L}_{\text {Truth }}\right)$ if its probability to be converted into cash is $100 \%$, that is, null specificity, so it is cash already. On the other hand, an item that has null probability to be converted into cash is definitely not liquid (LFalse), or extreme high specific. Anywhere between two extremes is the gray zone $\left(\mathrm{L}_{j}\right)$, where the probability $(\mathrm{j})$ is $0 \%<\mathrm{j}<100 \%$. 


\section{FIGURE 1}

\section{Asset's liquidity paradox, a single dimensional vagueness case}

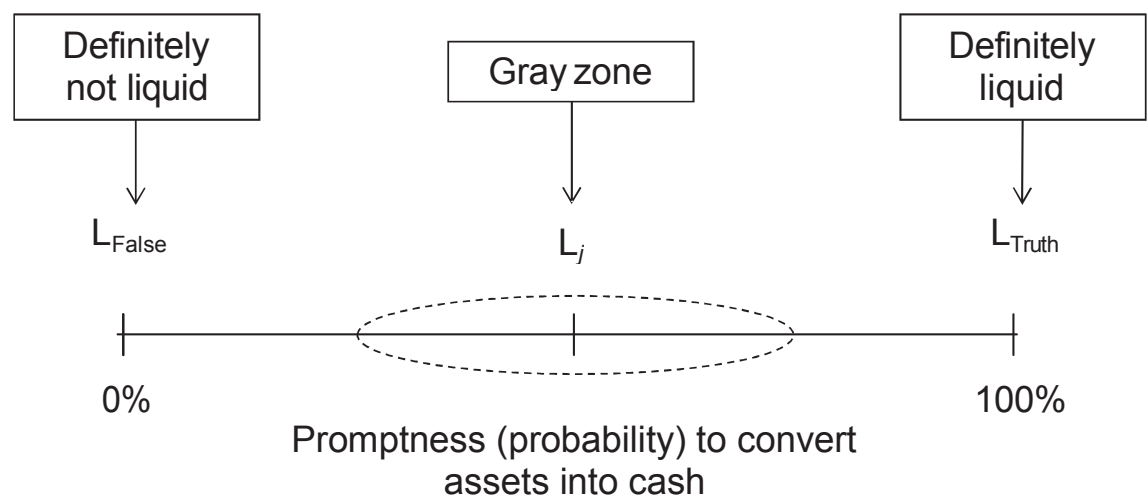

Where, $\mathrm{L}_{j}$ means any liquidity level different from definitely liquid and definitely not liquid.

\section{Source: Adapted from Penno (2008)}

To characterize the epistemic vagueness, based on Barnes $(1982)^{8}$, we state the asset's liquidity paradox as follows:

Considering that liquidity level of an asset is associated to its probability to be converted into a no-specific asset (e.g. cash)...

a liquidity level of $1 \%$ does not make an asset liquid.

if a liquidity level of $1 \%$ does not make an asset liquid then a liquidity level of $2 \%$ does not. if a liquidity level of $2 \%$ does not make an asset liquid then a liquidity level of $3 \%$ does not. .... if a liquidity level of $99.99 \%$ does not make an asset liquid then a liquidity level of $100 \%$ does not.

A liquidity level of $100 \%$ does not make an asset liquid.

The later statement is clearly false.

As illustrated in figure 1, someone would purpose to create a third category including the (unidimensional) gray zone. This strategy is called trivalent logic and is criticized by Williamson (1997) because it does not "solve" the epistemic problem. Instead, the supervaluationism leads to higher-order vagueness problem (Williamson, 1999b), once it becomes necessary to define borderlines between definitely-true and indeterminate, and between definitely-false and indeterminate.

Notwithstanding Williamson critics, and besides the epistemic perspective, many-valued logic has been reasonably developed on the later decades, through a mathematical perspective, for instance the fuzzy logic and its software (ZADEH, 1965; ZEBDA, 1991). Accounting framework also tries to mitigate this problem: (i) creating others intermediary categories (what increase the epistemic problem), and (ii) recommending multi-criteria approach to classify

\footnotetext{
${ }^{8}$ According to Barnes (1982) there are two main conditions under which any argument is soritical: the series $<a_{1}, \ldots, a_{i}>$ must be ordered; the predicate ' $F$ ' must satisfy the following three constraints: (i) it must appear true of $a_{1}$, the first item in the series; (ii) it must appear false of $a_{\mathrm{i}}$, the last item in the series; and (iii) each adjacent pair in the series, $a_{n}$ and $a_{n+1}$, must be sufficiently similar as to appear indiscriminable in respect of ' $F$ ' - that is, both $a_{n}$ and $a_{n+1}$ appear to satisfy ' $F$ ' or neither do. Under these conditions ' $F$ ' will be soritical relative to the series $\left\langle a_{1}, \ldots, a_{i}\right\rangle$ and any argument of the above form using ' $F$ ' and $\left\langle a_{1}, \ldots, a_{i}\right\rangle$ will be soritical.
} 
items. Implicit on this strategy accounting framework induces the usage of more than one dimensions, in order to reduce some degree of ambiguity or vagueness, as will be demonstrate on the next section.

\section{MULTI-DIMENSIONAL VAGUENESS ON BALANCE SHEET'S LEFT SIDE}

In respect to assets, the main concern of IASB's Framework for the Preparation and Presentation of Financial Statements (hereafter, the Framework) is their recognition and valuation. Notwithstanding emphasis given by standard setters on the concept of asset items measurement criteria and valuation, there are few discussions about asset's presentation (classification) on balance sheet (statement of financial position). The actual usage of inventory, PPE, and intangible asset classifications do not elucidate the capacity that some asset items have to provide future economic benefits, through time. In practice, a specific transaction would be classified according to characteristics (accepted by the Framework) that not necessarily will be correlated with the asset's real potential cash inflows. It occurs because, in some cases, there is a weak relation between characteristics suggested by the Framework to discriminate assets and their real liquidity (promptness conversion of an asset with specificity higher than zero into another asset no specific or, at least, less specific). This weak sensitivity is created by epistemic and semantic vagueness.

Trying to mitigate multi-dimensional vagueness, accounting literature (including standards) suggests the following dimensions to segregate asset items among inventory, PPE, and intangible asset: (i) it is the asset item, itself, that provides economic benefits; (ii) capacity to provide economic benefits constrained to only one single transaction; (iii) the asset has physical form, or it is intangible. In spite of that blend of features (multi-dimensional approach), the gray zone is still present on the left side of the balance sheet.

In this paper we define the (multi-dimensional) gray zone as the extension in the liquidity level which, due to epistemic and semantic vagueness problems, we cannot assert, consistently, that one typical transaction is more (less) liquid than another.

While inventory ${ }^{9}$ uses to be presented at the current asset section of the balance sheet, not regarding if it is expected to be recovered more than twelve months after the reporting period; $\mathrm{PPE}^{10}$ and intangible assets (including, copyrights) ${ }^{11}$ use to be presented at the noncurrent asset section of the balance sheet, not regarding if they are expected to provide some economic benefits within twelve months from the reporting period.

\footnotetext{
${ }^{9}$ According to IAS 2 (paragraph 8): "inventories encompass goods purchased and held for resale including, for example, merchandise purchased by a retailer and held for resale [...] finished goods produced, or work in progress being produced [...] materials and supplies awaiting use in the production process [... and] costs of the service $[. .$.$] for which the entity has not yet recognized the related revenue". In accordance to Kieso, Weygandt$ and Warfield (2005, p.368), "[i]nventories are asset items held for sale in the ordinary course of business or goods that will be used or consumed in the production of goods to be sold".

${ }^{10}$ According to IAS 16 (paragraph 6): "Property, plant and equipment are tangible items that: (a) are held for use in the production or supply of goods or services, for rental to others, or for administrative purposes; and (b) are expected to be used during more than one period." According to Kieso, Weygandt and Warfield (2005, p.470), property, plant, and equipment (PPE) "include land, building structures (offices, factories, warehouses) and equipment (machinery, furniture, tools) [...] the major characteristics of property, plant, and equipment are: (1) they are acquired for use in operations and not for resale [...] (2) they are long-term in nature and usually subject to depreciation [...] (3) they possess physical substance".

${ }^{11}$ According to Kieso, Weygandt and Warfield (2005, p.570-3), "intangible assets have two main characteristics: (1) they lack physical substance; and (2) they are not financial instruments", and its major categories are: marketing-related (trademark, and trade or brand name); customer-related (customer list); artistic-related (copyright); contract-related (franchise, licenses or permits); technology-related (patent); goodwill. Paragraph 8 of IAS 38 shortly defines an intangible asset as "an identifiable non-monetary asset without physical substance".
} 
Accounting literature (for example, see footnotes 9-11) suggests that the main distinctions between inventory and PPE are: (i) it is the inventory item, itself, that provides economic benefits; while PPE provides economic benefits indirectly (through the sale of finished goods produced at the factory and with machinery and tools). This two-dimensional distinction, although generally accepted, is embedded on vagueness that provides a (multidimensional) gray zone among inventories, PPE or intangible assets; because (ii) a certain item of inventory has its capacity to provide economic benefits constrained to only one single transaction, while PPE and intangible assets provide economic benefits that are not constrained to any number of transaction, but to their economic life, and finally (iii) PPE are tangible assets while intangible assets (as the name suggest) does not have physical form.

Following, we present examples of transactions that lay on the gray zone. First, Altria Group Inc. (Philip Morris) and British American Tobacco (BAT) classify their entire leaf tobacco inventory, which have an operating cycle that exceeds 12 months, as a current asset although part of such inventory, because of the duration of the aging process, ordinarily would not be utilized within one year. Altria and BAT presentation criteria are in accordance to Epstein and Jermakowicz $(2007,47)$, who say "[i]nventories [...] should still be classified as current asset [...] even if [they are] not expected to be realized within twelve months from the balance sheet data". Curiously, Souza Cruz S/A, one of BAT subsidiaries that follows Brazilian-GAAP, recognizes a part of leaf tobacco inventory as a non-current asset.

As a second example, according to the definition provided by IAS 16, PPE are also tangible assets ${ }^{12}$ held for rental to others. In this case, for-rental $\mathrm{PPE}^{13}$ item provides economic benefits by itself, so, in this particularity, PPE becomes similar to finished goods inventory. On the other hand, differently from inventory, and similarly to ordinary PPE items, for-rental PPE's capacity to provide economic benefits is not bounded to only one single transaction (or use). Examples of for-rental PPE items are those related to operating leases, that, among other characteristics, are rented on lease terms substantially inferior to the assets' economic life and are not specialized to one single lessee, so they have the potential to be rented $n$ times, through $n$ transactions. Considering that some rental transactions may take place, and provide cash inflows, during the first twelve months from balance sheet date (or acquisition/installment), does the traditional classification (as non-current asset) create some misinformation on performance measurement contracts based on liquidity? ${ }^{14}$

\footnotetext{
${ }^{12}$ Although, neither IAS 2 nor accounting textbooks constrain inventory's definition to tangible asset, examples presented on accounting literature and on AICPA's survey - Accounting Trends and Techniques (AICPA, 2008) - are all related to items that possess physical substance. Through this perspective, inventory and PPE have another similarity, both are (or might be) tangible assets.

${ }^{13}$ Note that for-rental PPE is completely different from PPE item that became held for sale. Paragraph 68A of IAS 16 states that "an entity that, in the course of its ordinary activities, routinely sells items of property, plant and equipment that it has held for rental to others shall transfer such assets to inventories at their carrying amount when they cease to be rented and become held for sale", in this case, IFRS 5 is not applicable.

${ }^{14}$ In addition, let suppose that an item can also be used by the entity (its owner), on its normal operating activities (ordinary PPE), or rented to others (for-rental PPE). The allocating decision is based in accordance to demand: if the entity needs to use the item and it is not rented to others at that time, the entity uses that; and if third parties require that for rental, when it is not being used by the entity, the entity rents. Based on paragraph 6 of IAS 16, it should be classified as PPE, a typical non-current asset item, inducing a liquidity loss. That item has a hybrid capacity to provide cash inflows, those derived from rentals are directly provided by the item itself, and are clearly expected to start providing benefits within twelve months from balance sheet date. On the other hand, cash inflows derived from the usage of PPE (ordinary) items by the entity (its owner) are provided indirectly, and are not clearly expected to be provided within twelve months from balance sheet date.
} 
Finally, a third example: tradable intangible assets, like copyrights over motion picture films and computer software developed by the entity for negotiation with third parties ${ }^{15}$. For instance, films have a hybrid capacity to provide cash inflows, immediately and directly (by licensing agreements to movie theaters), as well as on the long run (also via licensing agreements, but, through different windows, markets and territories), so, the film producer "should disclose in the financial statements notes, the costs portions, of its completed films that are expected to be amortized during the upcoming operating cycle, which is presumed to be in twelve months" (paragraph 51 of SOP 00-2).

We argue that the traditional classification of balance sheet (current/non-current assets and liabilities) has being widespread used as a straitjacket, and that may be explained as a blind compliance to accounting regulation that meanwhile reduces some firms' and auditors' transaction costs, since it provides a more "objective" accounting information, it compromises accounting information relevance on accessing firm's performance. As argued by Wyatt (2005), limiting the choice to record and classify items on balance sheet "would thus tend to reduce, rather than improve, the quality of balance sheet and investors' information set".

These dimensions are insufficient, so on the next section we identify five arrangements which accommodate contemporary economic transactions.

\section{TYPICAL PROPERTY RIGHT ARRANGEMENTS}

We cannot build our analysis based on accounting standards, because those standards have per se vagueness. So, we had to find economic transactions' characteristics trough which assets are negotiated. An asset is a multi-dimensional bundle of attributes (BARZEL, 1989) with potential to provide cash inflows constrained by efforts to mitigate contracting hazards. Firms choose arrangements to mitigate contractual hazards (CROCKER; MASTEN, 1988).

The distribution of property rights over the delineable and verifiable attributes of an asset in a supply chain and the arrangements that coordinate them are related to risk sharing among the agents in the supply chain and to liquidity (promptness to provide cash inflows). Those set of rights' arrangements may be kept by the firm or distributed/negotiated (based on asset's primary destination): (i) assets that are held and explored to create products or services, but that will not be transferred (at least, primarily), and (ii) assets that are used (negotiated) to generate revenue through transference of its usage right to others.

The rights' transference intensity defines the level of transference of each attribute from vendor to buyer, which flows on a gradient structure. Rights' transference goes from one extreme, where a single attribute is transferred (e.g. a car rental transaction for the weekend), to another, where all property rights are transferred, inclusive the residual control rights over the good (e.g. a finished good sale transaction). Some negotiated attributes are exclusive and others not. Configurational approach (see footnote 7) leads us to identified five feasible and typical arrangements, all of them internally homogeneous and observable in the contemporary real world: full transference (FT), full transference with warranties (FTw), partial transference (PT), simultaneous partial transferences (PTs), and no-transference (NT).

When a firm's asset has none of its attributes transferred, this asset is arranged within a typical NT (no-transference) arrangement. The vendor maintains, with exclusivity, all property rights over this asset, and uses that to realize his activities. Some assets have potential to aggregate more value with transference of a limited number of attributes, than being retaining with the vendor. In these cases, the vendor transfers at least one attribute

\footnotetext{
${ }^{15}$ Motion picture films and computer software are examples of internally generated intangible items which costs of creation are recognized as intangible assets, exclusive those costs which would be analogous to research.
} 
(within $n$ contractible attributes) to buyers; however the vendor retains residual control rights over the asset. In a typical PT (partial transference) arrangement, the transferred attribute generally has physical form, consequently only one buyer can beneficiate itself with the services provided by that attribute. For instance, a car rental ("vendor") maintains the right to sell its cars and to collect rental revenues; since the rental agreement transfers to the lessee ("buyer") the right to use the car, constrained to usage conditions (responsibility over fines). In case of non-physical attributes, the same logic is valid for exclusive usage rights. Contrarily, when there is not an exclusivity agreement, and there is no physical form restriction (intangible attributes), a given attribute may be transferred simultaneously to more than one "buyer". The typical PTs (simultaneous partial transferences) arrangement includes brand usage rights, for example, through a franchising contract.

In the most common arrangement in a modern society, vendor transfers residual control rights over a good to a buyer, but for at least one attribute the vendor remains responsible, during certain time period, since contracted conditions are observed by the buyer. So, in a typical FTw (full transference with warranties) arrangement, the vendor provides a warranty for a good or service fully transferred to a buyer. These vendor's obligations are necessarily enforced by contracts or reputation. When attributes are fully measurable, in order that all potential future behavior of relevant attributes is internalized in price, buyer may accept to receive a good or service without any type of warranty. In an organized market, the typical FT (full transference) arrangement, as the classic caveat emptor transaction, is rarely, because at most of the time some extend of warranties (formal or informal, voluntary or compulsory) will exist.

So, we expected that the majority of contemporary economic transactions has been classified under these five types, representing additional information set to mitigate epistemic and semantic vagueness. In the next section, we explore the gray zone in order to intent do mitigate the liquidity's classification vagueness on balance sheet's left side.

\section{EXPLORING THE GRAY ZONE}

In this section we explore the gray zone. Using the strategy commented by Penno (2008), we started by an unidimensional approach and, step by step, added another dimensional by each time, to achieve what is called multi-dimensional approach. First, we substituted notations used on figure 1 and introduced account's categories discussed on this paper as well as those five arrangements presented on the previous section, as disclosed on Figure 2. 
FIGURE 2: Unidimensional approach to explore the gray zone

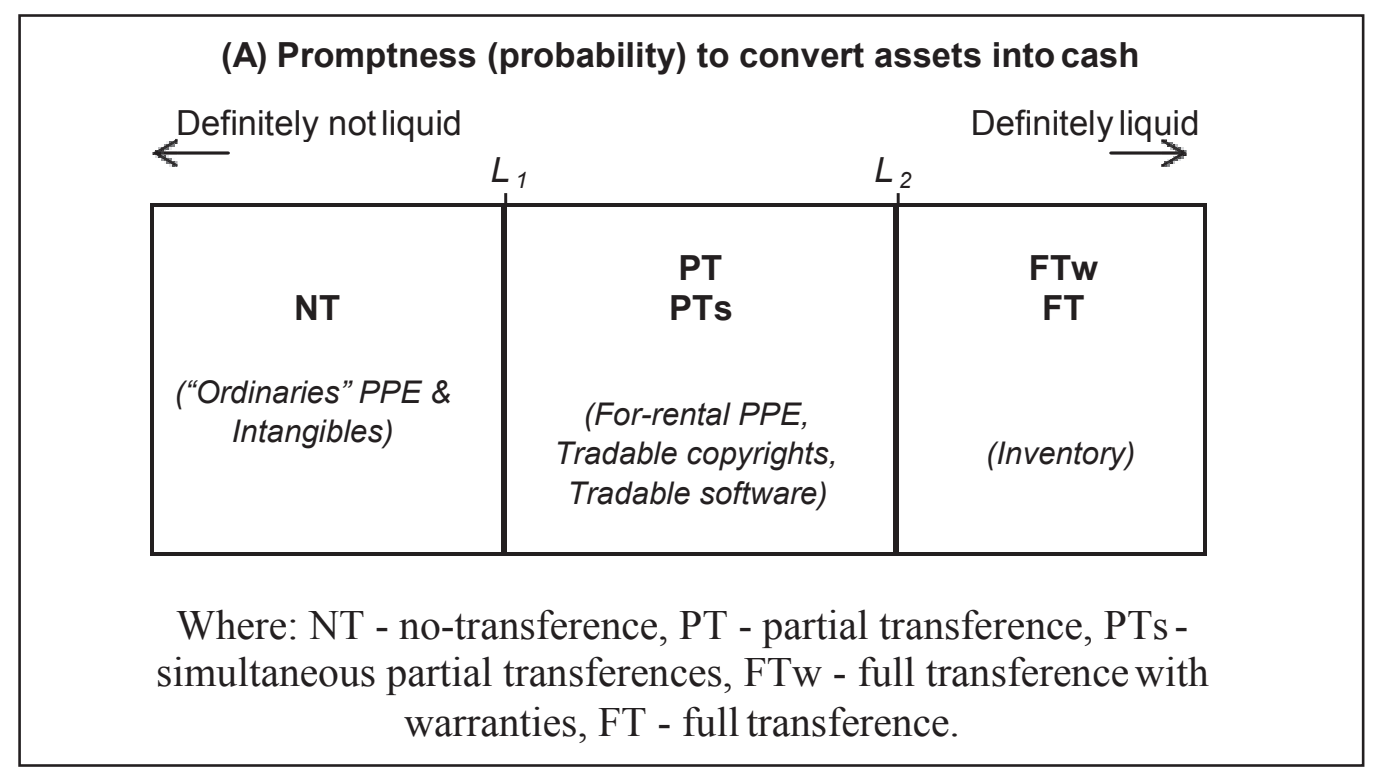

Figure 2 is still based on an unidimensional approach and it does not explore the gray zone, simply exchanges its labels by assets' examples.

But figure 2 is worthy because it alerts us to the need to identify a value for L1 to which NT is constantly less liquid than PT and PTs, and a value for L2 to which in any transaction PT/PTs are constantly less liquid than FT/FTw.

However, as explained on previous sections, liquidity suffers from Sōritēs paradox, and so, epistemic vagueness. Its borderlines are not clear, especially when the level of analysis is an individual actual transaction realized by a firm. Those limits would be estimated ex post by a technique as fuzzy logic. Even though, there would not be assured that a new transaction have the same historical liquidity as old similar transaction.

On one hand, no right over a NT arrangement is negotiated, so they do not provide any revenue by themselves. Ordinary PPE and ordinary intangible assets have this characteristic. On the other hand, the others four arrangements have the ability to provide revenues by themselves. This is the case of items like for-rental PPE, tradable intangible assets, and inventories. Thus, as presented on figure 3, dimension (B) helps on segregating NT arrangements (traditionally called ordinary PPE and ordinary intangible assets) from the other arrangements (PT, PTs, FT, and FTw). But it is not sufficient to segregate for-rental PPE, tradable copyrights and tradable software (PT and PTs) from inventory (FTw and FT).

The first two dimensions added are usual on accounting literature, and identified as relevant in asset's liquidity classification, they are: (A) promptness (probability) to convert assets into cash; (B) the item provides revenues directly (by itself) or indirectly. The third dimension (C) is related to the item's ability to provide revenue is constrained to one single transaction or to $n$ transactions. Even with this tri-dimensional approach, we show that it does not eliminate the vagueness problem, so we added an ideal dimension (D). 
FIGURE 3: Utopist dimension $k$ to mitigate the gray zone

(A) Promptness (probability) to convert assets into cash

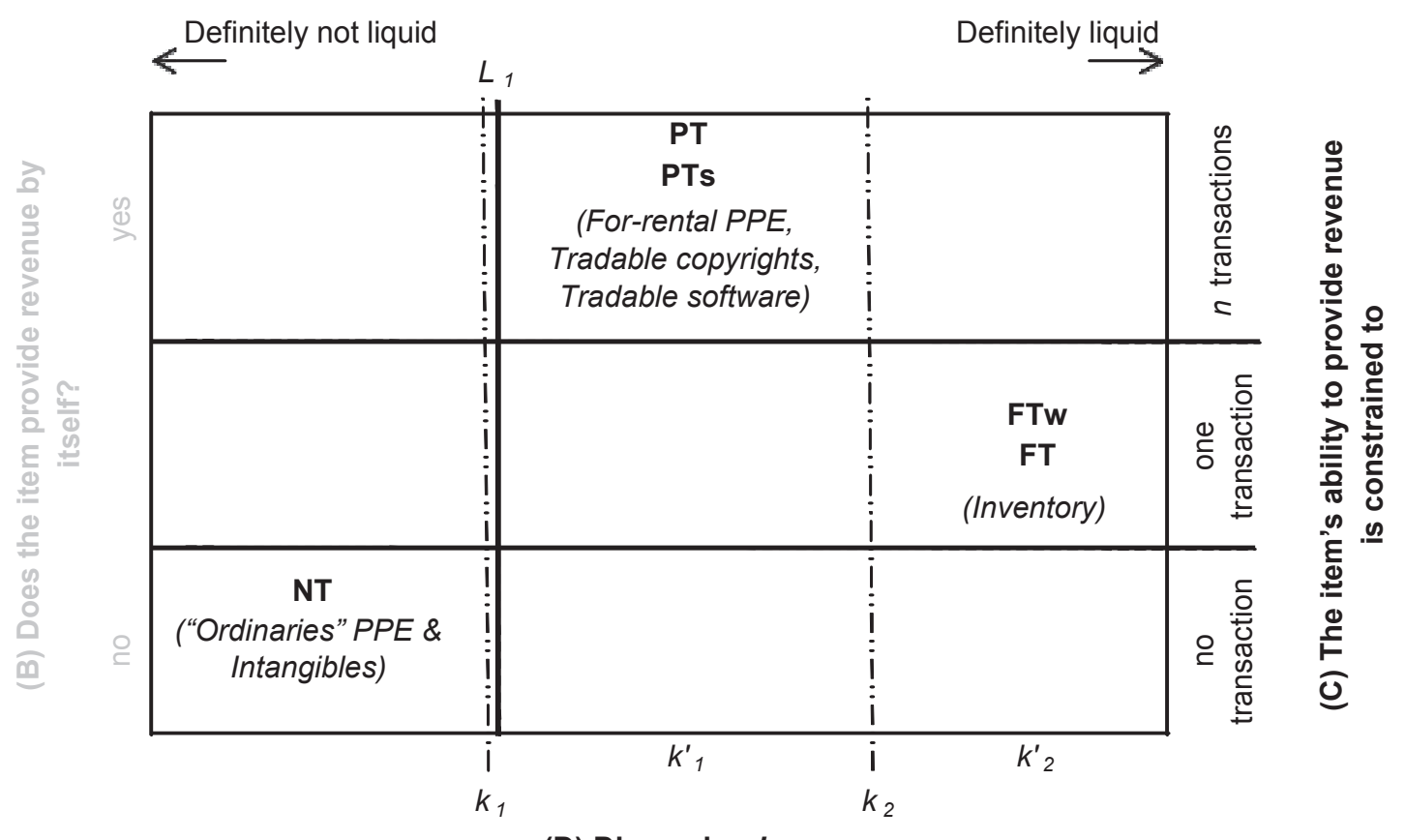

(D) Dimension $k$

Where: $k^{\prime} 1$ and $k^{\prime} 2$ are objective characteristics that consistently segregate PT and PTs from FTw and FT.

As discussed above, for NT, no right over attributes are negotiated, it is the case of ordinary PPE and ordinary intangible assets. So this items, generally with higher specificity and lower liquidity, do not provide any revenue by them, hence, there is not the number of transactions that constrains their abilities to provide future economic benefits, but their economic life. Any arrangement identified as FTw or FT (inventory) has its ability to provide revenue constrained to one single transaction. On the other hand, PT and PTs (for-rental PPE, and tradable intangible assets) are able to be segregated into many attributes in order to propitiate that the same asset item keeps providing revenues, transaction after transaction. Thus, as presented on figure 3, dimension (C), as like dimension (B), helps on segregating NT (ordinary PPE and ordinary intangible assets) from the gray zone. But dimension (C) advances in relation to dimension (B), since it helps to segregate PT/ PTs from FTw/FT.

Notice that since the addition of dimension (C), dimension (B) is not relevant anymore. Dimension (C) does not mitigate liquidity vagueness, because it does not guarantee that PT and PTs will be consistently less liquidity than all FTw and FT, although it mitigates vagueness related to traditional account categories borderlines. ${ }^{16}$ Although dimensions (A) and (C) are apparently sufficient to segregate all asset items analyzed in this paper, they are not sufficient to clearly segregate them in accordance to their liquidity level. Based on dimensions (A) and (C) we cannot assure nor generalize that FT and FTw are more liquid than PT and PTs. In the same way, we cannot assure that inventory items negotiated on FT arrangements are more (or less) liquid than items negotiated on FTw arrangements. We can assure neither that for-rental PPE items negotiated on PT arrangements are more (or less) liquid than tradable intangible asset items negotiated on PTs arrangements. That is so because

\footnotetext{
${ }^{16}$ Traditional account categories already distinguish PT and PTs from FT and FTw, but this distinction is not well done, once PT and PTs are interchanged with NT, since for-rental PPE is classified as PPE, and tradable intangibles are not taken apart from what we call "ordinary intangible assets".
} 
there are many other attributes related to assets liquidity besides those discussed on this paper, e.g. the asset's price, the firm's main activity, customer's wealth and preference, governmental regulation, market competition etc.

To mitigate liquidity vagueness associated to arrangements level (FT, FTw, PT, and PTs), ideally, there should be added one final dimension that segregates those arrangements consistently, at least in pairs (FT and FTw from PT and PTs). The ideal dimension $k$, as presented on figure 3, must attend to one of the following conditions: (i) the dimension should be measurable quantitatively, or (ii) the dimension should be surrogated by an objective characteristic present in one pair, and not present in the other. A characteristic would be considered objective if it was verifiable either by managers or by external stakeholders.

Finally, the power of dimension $k$ to mitigate liquidity vagueness depends on the degree in which arrangements PT and PTs are consistently identified as less (or more) liquid than FTw and FT. Evidently, before we find this ideal dimension $k$, it is necessary the existence of a condition where every PT and PTs are consistently less (or more) liquid than all FT and FTw. "Unfortunately", there is no reasonable evidence that the characteristics that typify those arrangements are fully correlated, not weak correlated, with liquidity level.

We did not identify this ideal dimension $k$ able to segregate PT and PTs from FTw and FT, thus liquidity epistemic vagueness was not eliminated. So, we suggest that transactions related to PT and PTs arrangement become disclosed on notes to financial statements, if they materially affect financial ratios, especially if the firm is part on covenant agreements or if its executive bonus is associated to solvency ratios.

\section{EXPERIMENT}

Accounting standards interpretation and consequent assets' classification decisions are influenced by a variety of reasons, for example: by the variability in the meaning of the concept upon which decisions are based (HRONSKY; HOUGHTON, 2001); by prepares and auditors incentives to report aggressively or conservatively; by the description of transactions' underlying economic constructs; by prepares and auditors specialization (MAINES; WAHLEN, 2006); and by prepares and auditors interpretation of transactions' liquidity consequences to the entity. To verify if preparers consider that there is vagueness on balanced sheet's left side, we tested the following hypotheses:

Hia. On average, actual classification of, a priori, "definitely PPE cases", "definitely Intangible cases", and "definitely Inventory cases", significantly differ from gray zone classification. While actual classification of, a priori, gray zone cases classification does not differ.

$\boldsymbol{H}_{1} \boldsymbol{b}$. There is significant variability on gray zone assets classification decisions made by subjects on the basis of actual accounting standards.

$\boldsymbol{H}_{2}$. Subjects with an incentive to make an aggressive reporting decision are more likely to interpret more liberally a vague professional standard than will subjects with an inventive to make a conservative reporting decision.

$\boldsymbol{H}_{3}$ a. Among subjects with an incentive to make a conservatism reporting decision and that received a more detailed description of economic substances of transactions are more likely to interpret less liberally a vague professional standard than will subjects with the same incentive but that received a less detailed description of economic substances of transactions. 
$\boldsymbol{H}_{3} \boldsymbol{b}$. Among subjects with an incentive to make an aggressive reporting decision, the access to more detailed description of economic substances of transactions does affect "gray zone assets" classification.

\subsection{Research design and procedures}

Considering that Libby et al (2002) advised about the costs of using practitioners as experiment's subjects, we surrogated them by 175 MBA students enrolled on Accounting courses. Experiments concerned to classifications of assets among inventory, PPE and intangible assets. In order to avoid bias (cognitive), we discharged responses from subjects whose academic background does not include a bachelor even on Accounting, Business Administration, or Economics, and from those who do not work on any activity related to the preparation, auditing, or the usage of accounting information.

The experiments involved a $2 \times 2$ between-subject design. In order to test the incentives effects, half of the students, randomly selected, received a short hypothetical firm description. Subjects from one group would act as an accountant of a firm that is going through solvency problems and that is about to break covenant's current ratio threshold (aggressive accounting incentive). Subjects from the other group would act as an accountant of a firm that has a good financial situation, is not leveraged, and its audit committee has just induced the CEO to contract a Big-four audit firm which has a pervasive reputation to emit qualified opinion (conservative accounting incentive). Additionally, in order to test the effects of additional level of underlying economic constructs' information, a half of each group received one of the two levels of cases' description (synthetic description, or analytic description). The analytic description shows detailed economic arrangement's descriptions including one of five typical arrangements- NT, PT, PTs, FT, FTw - that represent information about economic constructs.

Research instruments were structured as follows. First, asked subjects' personal information: age, gender, course of bachelor, bachelor tenure, number of employees of the firm for which he works for, his position at this firm, position tenure, credits already studied at the MBA. Second, we presented a short hypothetical firm description (incentive). Then, IASB's definitions for inventory, PPE, and intangible assets (IAS 2, 16 and 38, respectively) were provided - but to avoid bias, we did not provide the source of those definitions. On the fourth section, 12 simplified cases related to the control of different assets were presented ${ }^{17}$.

Following, we asked subjects to classify those cases on two scales: on a dichotomy scale (where: 0 = inventory; 1 = PPE or Intangible assets); and on a five-points Likert scale to ask subjects about their level of conviction concerning to those classifications (where: $1=$ definitely inventory; 2 = probably inventory; 3 = indifferent; $4=$ probably PPE or probably intangible assets; and $5=$ definitely PPE or definitely Intangible assets) ${ }^{18}$.

Final sample was composed by 93 subjects, split into four groups as follows: (i) aggressive accounting incentive with synthetic description (20.4\%); (ii) aggressive accounting incentive with analytic description (29\%); (iii) conservative accounting incentive with

\footnotetext{
${ }^{17}$ Three of them are definitely classified, ex ante, as inventory, three as PPE, three as intangible assets, and other three - based on our point of view, discussed on the theoretical section of this paper - are on the gray zone (hereafter, "gray zone assets").

${ }^{18}$ Responses to the dichotomy scale were used to validate responses to the Likert scale. For instance, those subjects that answered "Inventory" to a certain case on the dichotomy scale, and answered "Definitely PPE or definitely Intangible assets" to the same case on the Likert scale, were discharged from the final sample. We also discharged from the final sample subjects that answered Inventory to cases that are, a priori, clearly related to PPE or Intangible assets, and vice-versa.
} 
synthetic description (26.9\%); and (iv) conservative accounting incentive with analytic description (23.7\%). Experiments were applied during MBA classes which present writers were not the lecturers. Although none of these writers was present at all sessions to ensure conformity of instructions and subject conditions, subjects were informed that they would not be evaluated by that. On average, subjects took 30 minutes to complete the instrument.

\subsection{Analyses and Results}

To test $\mathrm{H}_{1}$ a we ran a One-Sample $\mathrm{T}$ test, to compare all 12 cases classification on Likert scale. On the five-point Likert scale, we expected that Inventory assets were classified by subjects closer to 1 (definitely Inventory); PPE and Intangible assets were classified closer to 5 (definitely PPE or definitely Intangible); while gray zone assets were not classified closer to 1 nether to 5 , for instance, closer to 3 (indifferent). Table 1 shows that gray zone assets classification is not significant different from 3 (indifferent), while all other asset's classifications are. So, $\mathrm{H}_{1}$ a is not rejected, meaning that subjects classified as "indifferent" on Likert Scale those cases that were a priori classified as Gray Zone assets.

TABLE 1

\begin{tabular}{|c|c|c|c|c|c|c|c|c|c|}
\hline \multirow[b]{2}{*}{$N=90$} & \multicolumn{2}{|c|}{ Descriptive } & \multicolumn{2}{|c|}{ One-Sample Statistics } & \multirow[b]{2}{*}{$N=90$} & \multicolumn{2}{|c|}{ Descriptive } & \multicolumn{2}{|c|}{ One-Sample Statistics } \\
\hline & Mean & $\begin{array}{c}\text { Std. } \\
\text { Deviation }\end{array}$ & $\begin{array}{c}t(\text { Test } \\
\text { Value }=3)\end{array}$ & $\begin{array}{c}\text { Sig. } \\
\text { (2-tailed) }\end{array}$ & & Mean & $\begin{array}{c}\text { Std. } \\
\text { Deviation }\end{array}$ & $\begin{array}{c}\mathrm{t}(\text { Test } \\
\text { Value }=3)\end{array}$ & $\begin{array}{c}\text { Sig. } \\
\text { (2-tailed) }\end{array}$ \\
\hline case1 & 4.92 & 0.27 & 67.71 & 0.00 & case7 & 1.16 & 0.42 & -41.50 & 0.00 \\
\hline case2 & 4.94 & 0.23 & 80.08 & 0.00 & case8 & 1.10 & 0.30 & -59.74 & 0.00 \\
\hline case 3 & 4.89 & 0.32 & 56.70 & 0.00 & case9 & 1.03 & 0.18 & -103.30 & 0.00 \\
\hline case 4 & 4.59 & 0.56 & 26.97 & 0.00 & case10 & 3.04 & 1.62 & 0.26 & 0.79 \\
\hline case5 & 4.46 & 0.67 & 20.51 & 0.00 & case11 & 3.07 & 1.60 & 0.39 & 0.69 \\
\hline case6 & 4.83 & 0.43 & 40.39 & 0.00 & case12 & 3.07 & 1.56 & 0.40 & 0.68 \\
\hline
\end{tabular}

Cases 1,2,3 - PPE; Cases 4,5,6 - Intangibles; Cases 7,8,9 - Inventory; Cases 10,11,12 - Gray Zone

To test $\mathrm{H}_{1} \mathrm{~b}$, we ran Levene's test of equality of error variances, based on a split sample into two groups: a priori non-gray zone assets (cases 1 through 9), and a prior gray zone assets (cases 10,11, and 12). Table 2 indicates that there is significant difference on variances among those two groups classification. Hence, the null hypothesis of $\mathrm{H}_{1} \mathrm{~b}$ was rejected. It means that there is a significant amount of variability in the decision outcome based on actual accounting standards issued by the International Accounting Standards Board.

TABLE 2

\begin{tabular}{|c|c|c|}
\hline \multicolumn{3}{|c|}{ Levene's Test of Equality of Error Variances ${ }^{\text {(a) }}$} \\
\hline & & $\mathrm{N}$ \\
\hline \multicolumn{2}{|c|}{ non-gray a priori (cases 1 through 9 ) } & 834 \\
\hline \multicolumn{2}{|c|}{ gray a priori (cases 10,11 and 12 ) } & 279 \\
\hline \multicolumn{3}{|c|}{ Dependent Variable: Classif } \\
\hline $\mathrm{F}$ & df 1 & Sig. \\
\hline 1823.86 & 1111 & 0.000 \\
\hline
\end{tabular}


These two evidences demonstrate that the borderlines among Inventory, PPE and Intangible assets, defined by the IASB, are not clear and are not sufficient to classify Gray Zone assets (cases 10, 11, and 12).

To test $\mathrm{H}_{2}$ we ran ANOVA to compare the means of classifications of the three cases of gray zone assets between-subjects with incentive to report aggressively versus with incentive to report conservatively (table 3 ). Although classifications means are lower for subjects with incentive to report aggressively, than for subjects with incentive to report conservatively, mean differences are not statistically significant. Based on reviewed literature, we expected that accounting standards' vagueness would make room for justifications of aggressive accounting practices in accordance to practitioners and managers incentives.

TABLE 3

\begin{tabular}{|c|c|c|c|c|c|c|c|c|}
\hline \multicolumn{5}{|c|}{ Descriptives } & \multicolumn{4}{|c|}{ ANOVA } \\
\hline & & $\mathrm{N}$ & Mean & $\begin{array}{c}\text { Std. } \\
\text { Deviation }\end{array}$ & & $\begin{array}{r}\text { Sum of } \\
\text { Squares }\end{array}$ & $\begin{array}{l}\text { Mean } \\
\text { Square }\end{array}$ & F (Sig.) \\
\hline \multirow[t]{2}{*}{ case 10} & CONSERVATIVE & 47 & 3.09 & 1.64 & Between Groups ${ }^{1}$ & 0.17 & 0.17 & $0.06(0.8)$ \\
\hline & AGRESSIVE & 45 & 3.00 & 1.64 & Within Groups & 241.66 & 2.69 & \\
\hline \multirow[t]{2}{*}{ case11 } & CONSERVATIVE & 45 & 3.33 & 1.64 & Between Groups ${ }^{1}$ & 7.45 & 7.45 & $2.96(0.09)$ \\
\hline & AGRESSIVE & 46 & 2.76 & 1.54 & Within Groups & 224.37 & 2.52 & \\
\hline \multirow[t]{2}{*}{ case12 } & CONSERVATIVE & 47 & 3.19 & 1.58 & Between Groups ${ }^{1}$ & 2.09 & 2.09 & $0.84(0.36)$ \\
\hline & AGRESSIVE & 46 & 2.89 & 1.58 & Within Groups & 227.73 & 2.50 & \\
\hline
\end{tabular}

. Between Groups (combined), weighted

Alternatively, we suggest that the confirmation of $\mathrm{H}_{2}$, at significance level of $0,05 \%$, may be explained by subjects background knowledge of accounting. As for proxy of this background, we controlled by three factors: (i) if subject has a bachelor in Accounting or Business Administration or Economy; (ii) if subject works as financial report preparer or auditor or analyst; and (iii) if subject works as for at least three years on this position. Results for $\mathrm{H}_{2}$, based on accounting background sub-sample is not different from those results presented on Table 3, it is discussed latter on this paper.

To test $\mathrm{H}_{3}$ a we ran ANOVA to compare, among subjects with incentive to report conservatively, the variability of classifications of the three cases of gray zone assets betweensubjects that received detailed information (analytic description) about economic substance over those twelve cases versus subjects that did not receive detailed information (synthetic description). Classifications' standard deviations are not lower for subjects that had access to analytic information (except for case 10), and mean differences are not statistically significant, as presented on Table 4.

Based on reviewed literature, we expected that accounting standards' vagueness would be mitigated by additional information about transactions' economic constructs. Alternatively, we suggest that $\mathrm{H}_{3}$ a non confirmation may be explained by subjects accounting background knowledge. Results for $\mathrm{H}_{3} \mathrm{a}$, based on accounting background sub-sample is not different from those results presented - except by the fact that cases 10 and 11 classifications standards deviations became lower for subjects that received analytic description than for those that received synthetic description concerning transactions' economic substances ${ }^{19}$.

\footnotetext{
${ }^{19}$ May be this is so because our subjects are MBA students, and the knowledge background control was not sufficient to depurate databases, even after discharging inconsistent responses (for instance, those subjects that answered "Inventory" to a certain case on dichotomy scale, and answered "Definitely PPE or definitely Intangible assets" to the same case on the Likert scale, were discharged from the final sample, and those who answered Inventory to cases that are, a priori, clearly related to PPE or Intangible assets, and vice-versa). From 82
} 
To test $\mathrm{H}_{3}$ b we ran ANOVA to compare, among subjects with incentive to report aggressively, the variability of classifications of the three cases of gray zone assets betweensubjects that received detailed information (analytic description) about economic substance involving experimental cases versus subjects that did not receive detailed information (synthetic description). Classifications standard deviations are not lower for subjects that had access to analytic information, and mean classification differences are not statistically significant, as presented on Panel B of Table 4. Based on reviewed literature, we expected that additional information about transactions' economic constructs would not mitigated accounting standards' vagueness. As we expected, $\mathrm{H}_{3} \mathrm{~b}$ was not confirmed.

\section{TABLE 4}

\begin{tabular}{|c|c|c|c|c|c|c|c|c|}
\hline \multicolumn{9}{|c|}{ Panel A: $\mathrm{H}_{3} \mathrm{a}$ Test } \\
\hline & & $\mathrm{N}$ & Mean & $\begin{array}{c}\text { Std. } \\
\text { Deviation }\end{array}$ & & $\begin{array}{r}\text { Sum of } \\
\text { Squares }\end{array}$ & $\begin{array}{l}\text { Square } \\
\text { Means }\end{array}$ & F (Sig.) \\
\hline case 10 & $\begin{array}{r}\text { SYNTHETIC } \\
\text { ANALYTIC }\end{array}$ & $\begin{array}{l}25 \\
22\end{array}$ & $\begin{array}{l}3.08 \\
3.09\end{array}$ & $\begin{array}{l}1.78 \\
1.51\end{array}$ & $\begin{array}{l}\text { Between Groups }{ }^{1} \\
\text { Within Groups }\end{array}$ & $\begin{array}{r}0 \\
123.66\end{array}$ & $\begin{array}{r}0 \\
2.75\end{array}$ & $0.00(0.98)$ \\
\hline case 11 & $\begin{array}{r}\text { SYNTHETIC } \\
\text { ANALYTIC }\end{array}$ & $\begin{array}{l}25 \\
20\end{array}$ & $\begin{array}{c}3.4 \\
3.25\end{array}$ & $\begin{array}{l}1.61 \\
1.71\end{array}$ & $\begin{array}{l}\text { Between Groups }{ }^{1} \\
\text { Within Groups }\end{array}$ & $\begin{array}{r}0.25 \\
117.75\end{array}$ & $\begin{array}{l}0.25 \\
2.74\end{array}$ & $0.09(0.76)$ \\
\hline case 12 & $\begin{array}{r}\text { SYNTHETIC } \\
\text { ANALYTIC }\end{array}$ & $\begin{array}{l}25 \\
22\end{array}$ & $\begin{array}{c}3.36 \\
3\end{array}$ & $\begin{array}{l}1.41 \\
1.77\end{array}$ & $\begin{array}{l}\text { Between Groups }{ }^{1} \\
\text { Within Groups }\end{array}$ & $\begin{array}{r}1.52 \\
113.76\end{array}$ & $\begin{array}{l}1.52 \\
2.53\end{array}$ & $0.60(0.44)$ \\
\hline \multicolumn{9}{|c|}{ Panel B: $\mathbf{H}_{3} b$ Test } \\
\hline & & $\begin{array}{c}\text { crip } \\
\mathrm{N}\end{array}$ & $\begin{array}{l}\text { ives } \\
\text { Mean }\end{array}$ & $\begin{array}{c}\text { Std. } \\
\text { Deviation }\end{array}$ & & $\begin{array}{l}\text { Sum of } \\
\text { Squares }\end{array}$ & $\begin{array}{l}\text { ANOVA } \\
\text { Square } \\
\text { Means }\end{array}$ & F (Sig.) \\
\hline case 10 & $\begin{array}{r}\text { SYNTHETIC } \\
\text { ANALYTIC }\end{array}$ & $\begin{array}{l}18 \\
27\end{array}$ & $\begin{array}{l}2.78 \\
3.15\end{array}$ & $\begin{array}{l}1.59 \\
1.68\end{array}$ & $\begin{array}{r}\text { Between Groups }{ }^{1} \\
\text { Within Groups }\end{array}$ & $\begin{array}{r}1.48 \\
116.52\end{array}$ & $\begin{array}{l}1.48 \\
2.71\end{array}$ & $0.55(0.46)$ \\
\hline case 11 & $\begin{array}{r}\text { SYNTHETIC } \\
\text { ANALYTIC }\end{array}$ & $\begin{array}{l}19 \\
27\end{array}$ & $\begin{array}{l}2.63 \\
2.85\end{array}$ & $\begin{array}{c}1.5 \\
1.59\end{array}$ & $\begin{array}{l}\text { Between Groups }{ }^{1} \\
\text { Within Groups }\end{array}$ & $\begin{array}{r}0.54 \\
105.83\end{array}$ & $\begin{array}{l}0.54 \\
2.41\end{array}$ & $0.22(0.64)$ \\
\hline case 12 & $\begin{array}{r}\text { SYNTHETIC } \\
\text { ANALYTIC }\end{array}$ & $\begin{array}{l}19 \\
27\end{array}$ & $\begin{array}{l}3.11 \\
2.74\end{array}$ & $\begin{array}{c}1.41 \\
1.7\end{array}$ & $\begin{array}{l}\text { Between Groups }{ }^{1} \\
\text { Within Groups }\end{array}$ & $\begin{array}{r}1.48 \\
110.97\end{array}$ & $\begin{array}{l}1.48 \\
2.52\end{array}$ & $0.59(0.45)$ \\
\hline
\end{tabular}

. Between Groups (combined), weighted.

\section{FINAL REMARKS}

Since real liquidity level of an asset is not observable ex ante by all agents that transact with the firm (external agents nor internal agents), account categories do not anticipate future cash flows for all possible contingencies, thus the Framework recommends the usage of some asset's features as its proxy of liquidity level. So, the liquidity level is signaled to external agents by that classification (based on those features). We highlighted the existence of liquidity vagueness on balance sheet's left side, i.e. we identified the gray zone. The use of those features is influenced by this overlapping (gray) zone, because the discriminate power offered by those features is weak. The lump-sum strategy adopted by accounting standards, concerned to PPE and intangible assets, leads to misrepresentation of for-rental PPE, tradable

discharged observations, only $9.8 \%$ were from subjects that got other bachelor degree from Accounting, Business Administration, or Economy; 56.1\% were from subjects that do not work as preparer, auditor neither analyst of financial report; and 29\% were from subjects that have less than three years professional experience on their activities related to the preparation, audit or analysis of financial report. 
copyrights and tradable computer software (PT and PTs), since they are more similar to inventory (FT and FTw) than to "ordinaries" PPE and intangible assets (NT).

Our tests shown that IAS 2, 16 and 38 are vague about the "proper" classification of assets that are straight associated to the firm's operating activity and provide revenue by itself but their capacity to provide revenue is not constrained to one single transaction. Subjects presented a great variability when classified them as Inventory or as PPE / Intangible asset. Although, contrarily to behavioral accounting and judgment and decision making literatures, we did not identify how incentive and transactions description affect their classifications. For future research, we suggest to ran the same experiments with financial statement prepares and auditors as subjects, and investigate if incentive and transactions description really do not affect classifications, or if evidences collected from MBA students are biased by their basic (superficial) knowledge of finance and accounting.

We proposed that material transactions related to PT and PTs arrangements, become disclosed on notes to financial statements, in order to allow managers and external stakeholders to access firm's real solvency status.

\section{REFERENCES}

AMERICAN INSTITUTE OF CERTIFIED PUBLIC ACCOUNTANTS (AICPA). Accounitng Trends and Techniques: presenting and analyzing financial reporting practices. $62^{\text {nd }}$ edition. New York, NY: AICPA, 2008.

Accounting by Producers and Distributors of Films. Statement of Position 00-2. New York, NY: AICPA, 2000.

ANTHONY, R.; REECE, J. S. Accounting Principles. $6^{\text {th }}$ edition. Homewood, Illinois: Irwin, 1989.

BARNES, J. Medicine, Experience and Logic, in J Barnes, J Brunschwig, M F Burnyeat \& M Schofield (eds.) Science and Speculation, Cambridge: Cambridge University Press, 1982.

BARTH, M. E. Global Financial Reporting: Implications for U.S. Academics. The Accounting Review, 83(5), pp. 1159-79, 2008.

BARZEL, Y. Economic Analysis of Property Rights. New York: Cambridge University Press, 175 p, 1989.

CHOUDHRY, M.; FABOZZI, F. J. Originating Collateralized Debt Obligations for Balance Sheet Management. The Journal of Structured and Project Finance, fall, pp. 32-52, 2003.

CROCKER, K. J.; MASTEN, S. E. Mitigating Contractual Hazards: Unilateral Options and Contract Length. RAND Journal of Economics, 19(3), pp. 327-43, 1988.

CUCCIA, A. D.; HACKENBRACK, K.; NELSON, M. W. The ability of professional standards to mitigate aggressive reporting. The Accounting Review, 70(2), pp. 227-48, 1995.

DEMSETZ, H. A Framework for the Study of Ownership. In Ownership, Control, and the Firm. Oxford: Basil Blackwell, 1988.

DOTY, D. H.; GLICK, W. H. Typologies as a Unique Form of Theory Building: Toward improved understanding and modeling. Academy of Management Review, 19, pp. 230-51, 1994.

EPSTEIN, B. J.; JERMAKOWICZ, E. K. IFRS 2007: interpretation and application of International Financial Reporting Standards. New Jersey: Wiley, 2007. 
FINANCIAL ACCOUNTING STANDARDS BOARD (FASB). Qualitative Characteristics of Accounting Information. Statement of Financial Accounting Concepts $\mathrm{N}^{\circ}$. 2. Norwalk, CT: FASB, 1980.

Financial Reporting by Producers and Distributors of Motion Picture Films. Statement of Financial Accounting Standards N ${ }^{\circ}$. 53. Norwalk, CT: FASB, 1981.

Rescission of FASB Statement No. 53 and amendments to FASB Statements No. 63, 89, and 121. Statement of Financial Accounting Standards $N^{0}$. 139. Norwalk, CT: FASB, 2000 .

HOPKINS, P. The effect of financial statement classification of hybrid financial instruments on financial analysts' stock price judgments. Journal of Accounting Research, 34, supplement, pp. 33-50, 1996.

HRONSKY, J. J. F.; HOUGHTON, K. A. The meaning of a defined accounting concept: regulatory changes and the effect on auditor decision making. Accounting, Organizations and Society, 26, pp.123-39, 2001.

HUNTON, J.; MCEWEN, R. An assessment of the relation between analysts' earnings forecast accuracy, motivational incentives and cognitive information search strategy. The Accounting Review, 72(4), pp. 497-515, 1997.

INTERNATIONAL ACCOUNTING STANDARDS BOARD (IASB). Framework for the Preparation and Presentation of Financial Statements. London, UK: IASB, 2001.

Inventories. IAS 2, 2004a.

Property, Plant and Equipment. IAS 16,2004b.

Intangible Assets. IAS 38,2004c.

. Non-current Assets Held for Sale and Discontinued Operations. IAS 5,2004d.

Evaluating the Substance of Transactions Involving the Legal Form of a Lease.

Standing Interpretations Committee Interpretation 27, 2004e.

. Determining whether an Arrangement Contains a Lease. IFRIC 4, $2004 \mathrm{f}$.

Presentation of Financial Statements. IAS.1, 2005a.

Leases. IAS 17, 2005 b.

JOSKOW, P. L. Vertical Integration and Long-Term Contracts: The case of Coal Burning Electric Plants, Journal of Law, Economics and Organization, 80, pp. 33-80, 1985.

KEEFE, R. Vagueness by Numbers. Mind, 107(427), pp. 565-79, 1998.

Vagueness without Context Change. Mind, 107(462), pp. 275-92, 2007.

KIESO, D. E.; WEYGANDT, J. J.; WARFIELD, T. D. Intermediate Accounting. $11^{\text {th }}$ edition. New Jersey: Wiley, 2005.

LIBBY, R.; BLOOMFIELD,R.; NELSON, M. Experimental research in financial accounting. Accounting, Organizations and Society, 27, 775-810, 2002.

MAINES, L.; WAHLEN, J. The nature of accounting information reliability: inferences from archival and experimental research. Accounting Horizons, 30(4), pp. 399-425, 2006.

MEYER, A. D.; TSUI A. S.; HININGS, C. R. Configurational Approaches to Organizational Analysis. Academy of Management Journal, 36, pp. 1175-95, 1993. 
MILLER, D. Notes on the Study of Configurations. Management International Review, 39 (special issue), pp. 27-39, 1999.

PENNO, M. C. Rules and Accounting: vagueness in conceptual frameworks. Accounting Horizons, 22, pp. 339-51, 2008.

PSAROS, J. Do principles-based accounting standards lead to biased financial reporting? An Australian experiment. Accounting and Finance, 47, pp.527-50, 2007.

SUNDER, S. Economics of Fair Value. Accounting Horizons. 22(1), pp. 111-25, 2008.

WYATT, A. Accounting Recognition if Intangible Assets: theory and evidence on economic determinants. The Accounting Review. 80(3), pp. 967-1003, 2005.

WILliamsON, T. Précis of Vagueness. Philosophy and Phenomenological Research, 57(4), p.921-8, 1997.

Schiffer on the Epistemic Theory of Vagueness. Noûs, 33 (supplement: Philosophical Perspectives, 13, Epistemology), pp. 505-17, 1999a.

On the Structure of Higher-Order Vagueness. Mind, 108 (429), pp. 127-43, $1999 \mathrm{~b}$.

ZADEH, L. Fuzzy Sets. Information and Control, 8, pp. 338-53, 1965.

ZEBDA, A. The Problem of Ambiguity and Vagueness in Accounting. Behavioral Research in Accounting, 3, pp. 117-45, 1991. 